\title{
Increased frequency of CFTR gene mutations in sarcoidosis: a case/ control association study
}

\author{
Cristina Bombieri ${ }^{1}$, Maurizio Luisetti ${ }^{2}$, Francesca Belpinati ${ }^{1}$, Elisa Zuliani ${ }^{1}$, Anna Beretta ${ }^{2}$, \\ Jordan Baccheschi ${ }^{2}$, Lucio Casali ${ }^{2}$ and Pier Franco Pignatti ${ }^{1}$
}

\author{
${ }^{1}$ Section of Biology and Genetics, DMIBG, University of Verona; 37134 Verona, Italy; ${ }^{2}$ Institute of Respiratory \\ Diseases, IRCCS San Matteo Hospital, University of Pavia, Pavia, Italy
}

\begin{abstract}
A complete screening of the CFTR gene by DGGE and DNA sequencing was performed in patients with sarcoidosis. In 8/ 26 cases, missense and splicing CFTR gene mutations were found, a significant difference over controls $(9 / 89)$ from the same population $(P=0.014)$. The odds ratio for a person with a CFTR gene mutation to develop the disease is $3.95(1.18<O R<13.26)$. Seven different CFTR gene mutations were observed: R75Q, R347P, $621+3$ A/G, $1898+3$ A/G, L997F, G1069R, and a novel mutation which was detected in this study, 1991V. R75Q mutation was present in $3 / 26$ patients, a significant increase $(P=0.01)$ in cases over controls, indicating its preferential association with sarcoidosis. A trend towards disease progression was observed in patients with CFTR gene mutations compared to patients without mutations. These data suggest that CFTR gene mutations predispose to the development of sarcoidosis. European Journal of Human Genetics (2000) 8, 717-720.
\end{abstract}

Keywords: CFTR gene mutations; sarcoidosis; pulmonary diseases; cystic fibrosis; genotype-phenotype correlations

\begin{abstract}
Introduction
Sarcoidosis is a multisystem granulomatous disorder characterised by non-caseous granulomata and an accumulation of immunocompetent cells at sites of disease activity. ${ }^{1}$ The aetiology of the disease is not known, but there is a growing body of evidence strongly suggesting that in sarcoidosis, as in other complex traits, environmental factors may contribute to the onset of the disorder in genetically predisposed individuals. ${ }^{2} \mathrm{~A}$ genetic component in sarcoidosis is indicated by the varying incidence among different ethnic groups, and by the occurrence of familial clustering of cases. ${ }^{3,4}$ Furthermore, genetic factors are believed to play an important role in determining the pattern of the disease, its severity, and prognosis: in other words, genetic variation may underlie the different phenotypes of the disease. ${ }^{5}$ No linkage to a chromosomal region where candidate genes for two granulomatous disorders with clinical similarities to sarcoidosis are located has been observed in African-American sib pairs with
\end{abstract}

Correspondence: Dr Cristina Bombieri, Sezione di Biologia e Genetica, DMIBG, Università di Verona, Strada Le Grazie 8, I-37134 Verona, Italy. Tel: + 39045 8098673; Fax: + 390458098180 ;

E-mail: cristy@borgoroma.univr.it

Received 9 February 2000; revised 11 April 2000; accepted 25 May 2000 sarcoidosis. $^{6}$ During a CFTR gene mutation screening in pulmonary diseases, we previously analysed a group of patients with a variety of obstructive and non-obstructive pulmonary diseases. ${ }^{7}$ In that paper, we reported that $5 / 8$ $(62 \%)$ of sarcoidosis patients had a mutation in the CFTR gene. This high incidence in a limited number of patients prompted us to analyse a second enlarged series of patients to confirm the data. We now report that in 26 new patients with sarcoidosis there is an increased frequency of mutations in the CFTR gene. These data confirm the initial finding, and indicate that the CFTR gene may increase the genetic susceptibility to the development of the disease.

Preliminary findings were communicated at two international meetings. ${ }^{8,9}$

\section{Materials and methods Patients}

Twenty-six adult unrelated consecutive patients with sarcoidosis were collected. All patients were Italians of white ancestry, and living in a northern region of Italy (Lombardy). Diagnosis and assessment of sarcoidosis was performed according to the recently published guidelines. ${ }^{10}$ Chest 
radiographic staging was assessed according to De Remee. ${ }^{11}$ Twenty-three out of 26 patients had sarcoidosis confirmed by one or more biopsies. Two patients refused biopsy. Both were in chest radiologic stage II and they showed clinical features consistent with clinical diagnosis of sarcoidosis. In one patient, presenting with classical Löfgren's syndrome, confirmatory biopsy was not needed. ${ }^{10}$ For these reasons, the three patients with clinical diagnosis of sarcoidosis were included in our series (see Table1).

The control group was formed by 89 consecutive patients presenting to the same department for other pulmonary diseases ( 27 with chronic bronchitis, 25 with emphysema, 26 with lung cancer, four with active tuberculosis, five with bacterial pneumonia, two with spontaneous pneumothorax. ${ }^{7}$ All subjects were of the same ethnic and geographic origin as the sarcoidosis patients. In the control group, assessment of the underlying disease excluded the coexistence of sarcoidosis.

\section{Mutation analysis}

Genomic DNA was extracted from peripheral whole blood samples by standard methods. ${ }^{12}$ A complete analysis of all the 27 exons of the CFTR gene and their intronic flanking regions was performed by denaturing gradient gel electrophoresis (DGGE), as previously reported. ${ }^{7}$ By this method, individual genotypes were correctly determined for 73/74CFTR gene mutations not originally detected by DGGE, and located at different sites all along the gene, with a sensitivity of $98.6 \%$.
Mutations detected by DGGE analysis were identified by automatic DNA sequencing with the ABI Prism 377 sequence analyser (PE Applied Biosystems, Foster City, CA, USA). Moreover, individuals were genotyped for three intronic mutations: IVS8-6 $\mathrm{T}_{\mathrm{n}} \mathrm{N},{ }^{13}$ IVS8 $(\mathrm{TG})_{\mathrm{m}}-\mathrm{T}_{\mathrm{n}}{ }^{14} 3849+10 \mathrm{~Kb}$ $\mathrm{C} \rightarrow \mathrm{T}^{15}$

Analysis of the effect of mutations on splicing efficiency was performed with the use of the software BCM Gene Finder/HSPL, available on the Baylor College of Medicine Search Launcher website (http://dot.imgen.bcm.tmc. edu:9331).

\section{Statistical analysis}

The frequency of mutations was determined by patient counts. Differences between patients and controls were compared by Fisher's exact test, using the EPI Info software (version 5.01). A P value of less than 0.05 was considered to indicate statistical significance. From the previous finding of 5/8 sarcoidosis patients with CFTR gene mutations compared with 9/89individuals with other pulmonary diseases from the same population, ${ }^{7}$ it was calculated that a new sample of 28 patients would have the power of $80 \%$ to detect a CFTR gene effect with an odds ratio of 5 .

\section{Results}

We performed the complete DGGE analysis of the CFTR gene in the 26 patients with sarcoidosis. We found eight patients with mutations (30.8\%) in the CFTR gene, as reported in Table2, column 2. This frequency represents a significant

Table 1 Characteristics of the sarcoidosis patients ( $n=26$ )

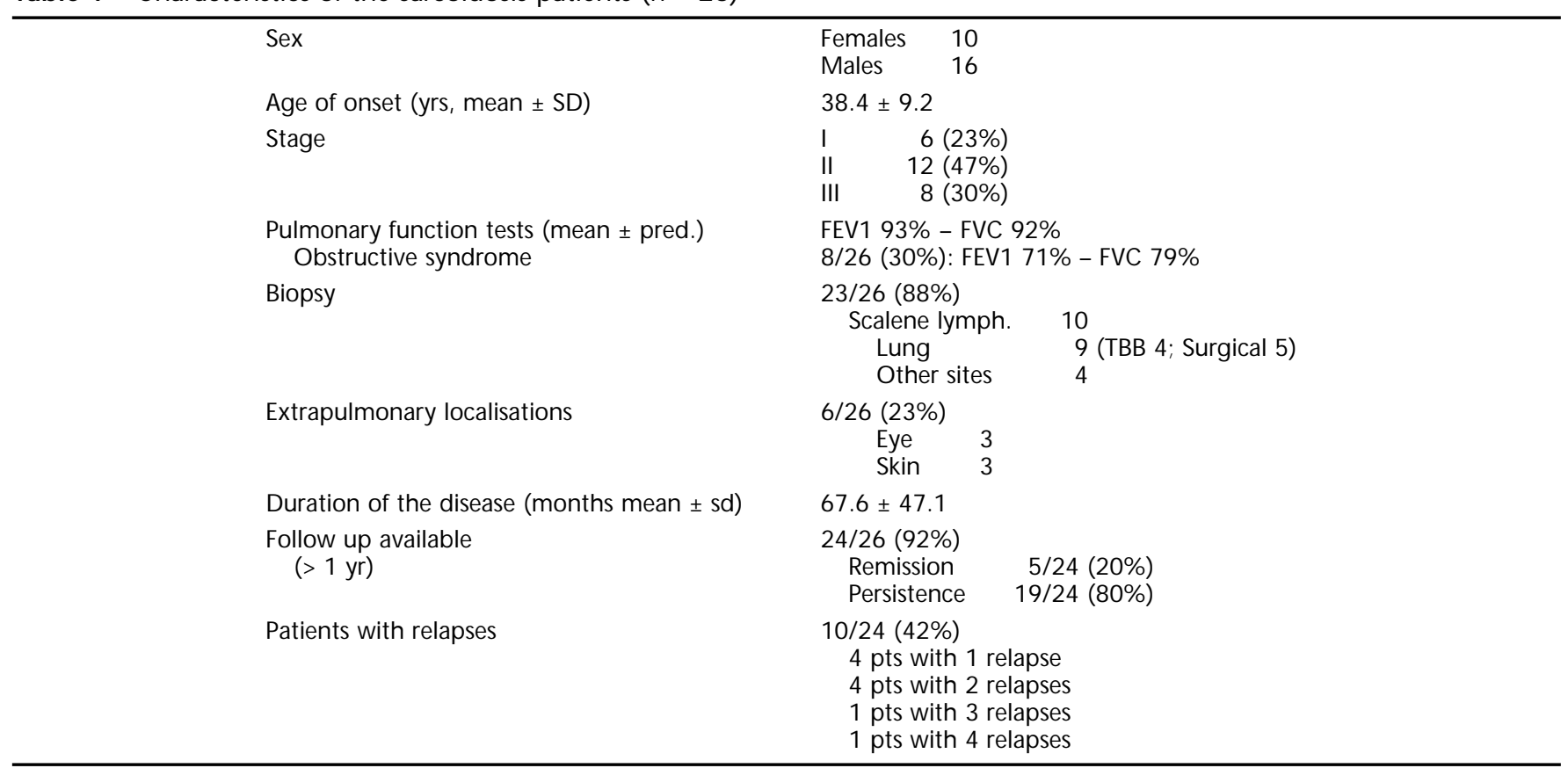


Table 2 CFTR genotypes of sarcoidosis patients $(n=26)$

\begin{tabular}{|c|c|c|c|c|}
\hline ID & $\begin{array}{l}\text { Missense and } \\
\text { splicing mutations }\end{array}$ & $\begin{array}{l}\text { Same sense and } \\
\text { intronic mutations }\end{array}$ & TGm-Tn & M470V \\
\hline 11 & G1069R & & $11-7 / 12-7$ & V/V \\
\hline 13 & R347P & $4404 \mathrm{C} / \mathrm{T}$ & $10-7 / 11-7$ & $\mathrm{M} / \mathrm{V}$ \\
\hline 15 & R75Q, 1898+3A/G & $186-13 \mathrm{C} / \mathrm{G}$ & $11-7 / 11-7$ & V/V \\
\hline 20 & $621+3 \mathrm{~A} / \mathrm{G}$ & & $10-7 / 10-7$ & $\mathrm{M} / \mathrm{M}$ \\
\hline 21 & $\mathrm{R} 75 \mathrm{Q}$ & & $11-7 / 11-7$ & V/V \\
\hline 27 & R75Q & $1716 \mathrm{G} / \mathrm{A}$ & $10-7 / 11-7$ & $\mathrm{M} / \mathrm{V}$ \\
\hline 31 & I991V & & $11-7 / 10-9$ & $\mathrm{M} / \mathrm{V}$ \\
\hline 32 & L997F & 4002 A/G, 3041-71 G/C & $10-9 / 11-9$ & $\mathrm{M} / \mathrm{V}$ \\
\hline 10 & & $4404 \mathrm{C} / \mathrm{T}$ & $11-7 / 11-7$ & V/V \\
\hline 18 & & $4002 \mathrm{~A} / \mathrm{G}$ & $11-7 / 12-7$ & $\mathrm{M} / \mathrm{V}$ \\
\hline 24 & & $3417 \mathrm{~A} / \mathrm{T}$ & $11-7 / 11-7$ & V/V \\
\hline 28 & & $4002 \mathrm{~A} / \mathrm{G}$ & $11-7 / 11-7$ & $\mathrm{M} / \mathrm{V}$ \\
\hline 34 & & $4002 \mathrm{~A} / \mathrm{G}$ & $11-7 / 11-7$ & $\mathrm{M} / \mathrm{V}$ \\
\hline 26 & & & $12-5 / 11-7$ & V/V \\
\hline 16 & & & $12-5 / 11-7$ & V/V \\
\hline 9 & & & $11-7 / 11-7$ & V/V \\
\hline 12 & & & $12-7 / 10-9$ & $\mathrm{M} / \mathrm{M}$ \\
\hline 14 & & & $11-7 / 10-9$ & $\mathrm{M} / \mathrm{V}$ \\
\hline 17 & & & $11-7 / 11-7$ & V/V \\
\hline 19 & & & $11-7 / 10-9$ & $\mathrm{M} / \mathrm{V}$ \\
\hline 22 & & & $10-7 / 11-7$ & $\mathrm{M} / \mathrm{V}$ \\
\hline 23 & & & $10-7 / 11-7$ & $M / V$ \\
\hline 25 & & & $10-7 / 11-7$ & $\mathrm{M} / \mathrm{V}$ \\
\hline 29 & & & $11-7 / 11-9$ & $\mathrm{M} / \mathrm{V}$ \\
\hline 30 & & & $11-7 / 11-7$ & V/V \\
\hline 33 & & & $11-7 / 12-7$ & V/V \\
\hline
\end{tabular}

The phase of the mutations is not known, as no segregation analysis was possible.

increase over controls (9/89; 10.1\%, Fisher's exact test, $P=0.014 ; O R=3.95,1.18-13.26$ ). Seven different missense or splicing mutations were found in the eight patients: R75Q, R347P, $1898+3 \mathrm{~A} / \mathrm{G}, 621+3 \mathrm{~A} / \mathrm{G}$, L997F, G1069R, 1991V. $\mathrm{R} 75 \mathrm{Q}$ was present in three patients (nos. 15, 21, 27). This is a significant increase over controls ( $3 / 26$ vs $0 / 89$, respectively, $P=0.01)$. R75Q has been described in $C F$ and related diseases, as disseminated bronchiectasis, ${ }^{7,16}$ and allergic broncho-pulmonary aspergillosis. ${ }^{17}$ One patient (no. 15) had two CFTR mutations (R75Q, $1898+3 \mathrm{~A} / \mathrm{G}$ ), but it was not possible to determine the phase. R347P is known to cause $C F^{18} 1898+3 \mathrm{~A} / \mathrm{G}$ has been found in $1 / 225$ genes from an Italian CF birth cohort we have previously described. ${ }^{19}$ The mutation $1898+3 \mathrm{~A} / \mathrm{G}$ abolishes the donor splice site (program cited in methods), with the possible consequence of exon 12 skipping from mature mRNA. $621+3$ A/G, L997F, and G1069R have been described in rare CF cases (Cystic Fibrosis Genetic Analysis Consortium website: http:/ /www.genet.sickkids.on.ca). Mutation $621+3$ A/G abolishes the donor splice site (program cited in Methods), with the possible consequence of exon 4 skipping from mature mRNA. L997F was found also in disseminated bronchiectasis. ${ }^{7,16}$ I991V is a novel mutation here described for the first time: it changes isoleucine to valine (both hydrophobic residues) in the second transmembrane domain. Isoleucine is a conserved residue in $4 / 5$ species, and valine is present in the fifth species. $^{20}$
The frequency of three common mutations which modify gene expression by alternative splicing (IVS8 $T G_{m}-T_{n}$ ), or by the efficiency of protein maturation (M470V) was not different from controls (see Table 2, columns4 and 5, respectively). In particular the IVS8-5T allele, which determines the production of increased amounts of transcripts lacking exon $9,{ }^{21}$ was found in $2 / 26$ patients, not statistically different from controls (12/89).

Several common polymorphisms not thought to cause $C F$, and including same sense mutations (1716 G/A, $2694 \mathrm{~T} / \mathrm{G}$, $3417 \mathrm{~A} / \mathrm{T}, 4002 \mathrm{~A} / \mathrm{G}, 4404 \mathrm{C} / \mathrm{T}$, and $4521 \mathrm{G} / \mathrm{A}$ ), and deep intronic mutations (186-13 C/G, $875+40 \mathrm{G} / \mathrm{A}$, IV S6 (GATT) and 3041-71 G/C) were found. No significant difference was detected between cases and controls for any of these common polymorphisms.

\section{Discussion}

These data indicate a significant excess of CFTR gene mutations in sarcoidosis patients. The data confirm, in a second series of patients from the same department, the excess of CFTR gene mutations found in our first report, in which $5 / 8$ patients with sarcoidosis were found to carry CFTR gene mutations. ${ }^{7}$ The total of this study plus the previous one is 13/34 sarcoidosis patients with at least one CFTR mutation $(\mathrm{P}=0.0006 ; \mathrm{OR}=5.5,1.88<\mathrm{OR}<16.41)$. With the exception of two novel mutations, E826K ${ }^{7}$ and 1991V (this study), all the mutations present in the 34 patients with sarcoidosis (R75Q, 621 + 3 A/G, R347P, DF508, $1898+3$ A/G, V754M, L997F, G1069R, 4382 del A) have also been observed in CF and CF-related diseases. Two recurrent mutations were observed in sarcoidosis: R75Q found in 3/34 patients and in $0 / 89$ controls $(P=0.02)$, and L997F found in 2/34 patients and in $0 / 89$ controls (NS). R75Q may therefore be a CFTR gene mutation characteristic of sarcoidosis.

When the 34 sarcoidosis patients are subdivided into those with $(C F T R+)$ and those without (CFTR-) CFTR gene mutations, and several clinical parameters are analysed, no significant differences were observed for mean age and symptoms at onset of the disorder, duration of the disease, outcome, and development of airflow obstruction. Interesting, but not significant, differences were the increase in CFTR + patients compared with CFTR-patients of:

1) chest radiologic stage I at entry ( $39 \%$ vs $24 \%)$;

2) relapses (58\% vs $44 \%)$;

3) extrapulmonary localisations ( $31 \%$ vs $19 \%$ ); and

4) chest radiologic stage progression (30\% vs $11 \%$ ), respectively.

This is an indication of a possible increased severity of the disease in the presence of CFTR gene mutations.

The mechanism of CFTR gene involvement in sarcoidosis aetiopathogenesis is unknown. Sarcoidosis is a complex disease in which genetic and environmental factors may play 
a role. Based on the fact that the granulomatous inflammation in sarcoidosis may be determined by a bacterium or a virus, and that the CFTR gene acts as a receptor for Pseudomonas aeruginosa ${ }^{22}$ and Salmonella typhi, ${ }^{23}$ an hypothesis is that the presence of CFTR gene mutations modify the effect of infection on disease onset and development. Further studies are needed to investigate the possible role of CFTR in determining a genetic predisposition to the disease.

\section{Acknowledgements}

This work has been funded by the Italian Ministry of Health, CF Project, law 548/93, the Italian Ministry of the University and Scientific and Technological Research, and the Italian CNR Strategic Project Biotechnology. We thank the ECCACF for providing mutation controls and the PCR mix for multiplex DGGE of the CFTR gene. CB was supported by CNR Strategic Project Biotechnology. FB was supported by CF Project law 548/93.

\section{References}

1 Semenzato G, Agostini C: Immunologic events in the development of interstitial lung disease: the paradigm of sarcoidosis. In: Schwarz M, King TE (eds). Interstitial Lung Disease. BC Decker: Hamilton, 1995, pp 229-250.

2 Petranyi GG: Susceptibility to autoimmune disease: a multigenic viewpoint. Immunol Today 1993; 13: 19-20.

3 Kitaichi M: Prevalence of sarcoidosis around the world. Sarcoidosis Vasc Diffuse Lung Dis 1998; 15: 16-18.

4 Rybicki BA, Maliarik MJ, Major M, Popovich J Jr, Iannuzzi MC: Genetics of sarcoidosis. Clin Chest Med 1997; 18: 707-717.

5 Newman LS, Rose CS, Maier LA: Sarcoidosis. N Engl J Med 1997; 336: 1224-1234.

6 Rybicki BA, Maliarik MJ, Bock CH et al: The Blau syndrome gene is not a major risk factor for sarcoidosis. Sarcoidosis Vasc Diffuse Lung Dis 1999; 16: 203-208.

7 Bombieri C, Benetazzo MG, Saccomani A et al: Complete mutational screening of the CFTR gene in 120 patients with pulmonary disease. Hum Genet 1998; 103: 718-722.

8 Bombieri C, Belpinati F, Luisetti M, Casali L, Pignatti PF: CFTR gene mutations in sarcoidosis patients. Am J Hum Genet 1999; 65: suppl. 4, Abs. 1475, pA265.

9 Luisetti M, Bombieri C, Belpinati $F$ et al: Excess of cystic fibrosis transmembrane conductance regulator (CFTR) gene mutations in sarcoidosis. Sarcoidosis Vasc Diffuse Lung Dis 1999; 16: suppl.1, Abs. p 20.
10 ATS/ERS/WASOG: Statement on Sarcoidosis. Sarcoidosis Vasc Diffuse Lung Dis 1999; 16: 149-173.

11 DeRemee RA: The chest roentgenology in sarcoidosis. Lieberman J (ed). Sarcoidosis. Grune \& Stratton: Orlando, FL, 1985; pp 117-135.

12 Sambrook J, Fritsch EF, Maniatis T: Molecular Cloning: a Laboratory Manual. 2nd edn, Vol. 3 CSH Press: 1989; E3-E4.

13 Chillon M, Casals T, Mercier B et al: Mutations in the cystic fibrosis gene in patients with congenital absence of the vas deferens. N Engl J Med 1995; 332: 1475-1480.

14 Strasberg PM, Friedman KJ, McGlynn-Steele L, Zielenski J, Ray PN: Rapid characterization of both the variable length 5,7 , or 9 polythimidine $(T)$ tract in intron 8 and the adjacent $C A$ repeat unit of the CFTR gene: use in DNA diagnosis. Am J Hum Genet 1997; 61: Suppl. 4, Abs. 2038, A348.

15 Highsmith WE, Burch LH, Zhou Z et al: A novel mutation in the cystic fibrosis gene in patients with pulmonary disease but normal sweat chloride concentrations. N Engl J Med 1994; 331: 974-980.

16 Girodon E, Cazeneuve C, Lebargy F et al: CFTR gene mutation in adults with disseminated bronchiectasis. Eur J Hum Genet 1997; 5: 149-155.

17 Weiner Miller P, Hamosh A, Macek M Jr et al: Cystic fibrosis transmembrane conductance regulator (CFTR) gene mutations in allergic bronchopulmonary aspergillosis. Am J Hum Genet 1996; 59: 45-51.

18 Rosenstein BJ, Cutting GR: The diagnosis of cystic fibrosis: a consensus statement. J Pediatr 1998; 132: 589-595.

19 Bonizzato A, Bisceglia L, Marigo C et al: Analysis of the complete coding region of the CFTR gene in a cohort of CF patients from North-Eastern Italy: identification of $90 \%$ of the mutations. Hum Genet 1994; 95: 397-402.

20 Tucker SJ, Tannahill D, Higgins CF: Identification and developmental expression of the Xenopus laevis cystic fibrosis transmembrane conductance regulator gene. Hum Mol Genet 1992; 1: 77-82.

21 Chu C-S, Trapnell BC, Curristin S, Cutting GR, Crystal RG: Genetic basis of variable exon 9 skipping in cystic fibrosis transmembrane conductance regulator mRNA. Nat Genet 1993; 3: 151-156.

22 Pier GB, Grout M, Zaidi TS: Cystic fibrosis transmembrane conductance regulator is an epithelial cell receptor for clearance of Pseudomonas aeruginosa from the lung. Proc Natl Acad Sci USA 1997; 94: 12088-12093.

23 Pier GB, Grout M, Zaidi T et al: Salmonella typhi uses CFTR to enter intestinal epithelial cells (Letter). Nature 1998; 393: 79-82. 